\title{
Eyelid ptosis
}

\section{Colin W. McInnes MD, Matthew Lee-Wing MD}

\section{Eyelid ptosis can obscure vision and impair activities of daily living}

Eyelid ptosis (descent of the eyelid margin) is common (Figure 1; video available at www.cmaj.ca/lookup/suppl/doi: 10.1503/cmaj.140579/-/DC1). ${ }^{1}$ The condition can obstruct vision and interfere with daily activities, such as driving and reading. ${ }^{1}$ Associated complaints include fatigue of the muscles in the forehead from continuous eyebrow elevation in an effort to raise the eyelids, neck soreness from tilting the head back to see, and appearing sad or tired.

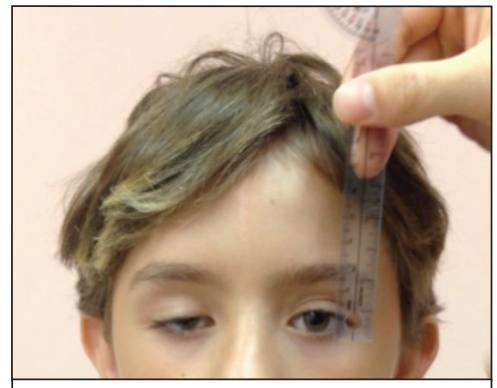

Figure 1: Eyelid ptosis in a 12-yearold boy.
Physical examination is usually sufficient to determine the diagnosis

The examination includes assessing the patient's visual acuity, extraocular movements and pupillary light reflex, marginal reflex distance (distance from the corneal light reflex to the upper eyelid margin, about 4-5 mm), upper eyelid crease (often absent in congenital and agerelated ptosis, and in people of Asian descent), palpebral fissure distance (about $9 \mathrm{~mm}$ ), and eyelid excursion (about $15 \mathrm{~mm}$; may be $0 \mathrm{~mm}$ in congenital cases). ${ }^{3}$

CMAJ invites submissions to "Five things to know about ..." Submit manuscripts online at http://mc.manuscriptcentral .com/cmaj

\section{Surgical treatment is highly effective}

Ptosis is typically corrected by outpatient surgery performed under local anesthetic, in which the position of the eyelid is adjusted and scars are hidden. Postoperative satisfaction is high, and many patients experience substantial improvement in functional status and appearance. $^{4}$

\section{References}

1. Zoumalan CI, Lisman RD. Evaluation and management of unilateral ptosis and avoiding contralateral ptosis. Aesthet Surg J 2010;30:320-8.

2. Lim JM, Hou JH, Singa RM, et al. Relative incidence of blepharoptosis subtypes in an oculoplastics practice at a tertiary care center. Orbit 2013;32:231-4.

3. Jindal K, Sarcia M, Codner MA. Functional considerations in aesthetic eyelid surgery. Plast Reconstr Surg 2014;134:1154-70.

4. Frueh BR, Musch DC, McDonald HM. Efficacy and efficiency of a small-incision, minimal dissection procedure versus a traditional approach for correcting aponeurotic ptosis. Ophthalmology 2004;111:2158-63.

\section{Many conditions can cause ptosis}

Ptosis is most commonly the result of age-related stretching and dehiscence of the levator aponeurosis $(60 \%)$. Other causes may be neurogenic (e.g., thirdnerve palsy, myasthenia gravis, Horner syndrome; $6 \%)$, traumatic $(11 \%)$, congenital (10\%), mechanical (e.g., eyelid tumours; $9 \%$ ) or myogenic $(4 \%){ }^{2}$ Pseudoptosis can be caused by dermatochalasis (excess eyelid skin that may hang over the margin). The underlying cause will affect the type and urgency of referral.

Some treatments are covered by public health insurance in Canada

Treatments for cases in which aging has resulted in a substantial defect in the visual field (e.g., moderate to severe ptosis or dermatochalasis) or is caused by non-aging-related conditions are typically covered. Eligibility criteria vary by province, but formal visual field testing by an optometrist is usually required.

\section{Competing interests: None declared.}

This article has been peer reviewed.

The authors have obtained patient consent

Affiliations: Section of Plastic Surgery (McInnes); Department of Ophthalmology (Lee-Wing), University of Manitoba, Winnipeg, Man.

Correspondence to: Colin McInnes, cmcinnes23 @ gmail.com

CMAJ 2015. DOI:10.1503/cmaj.140579

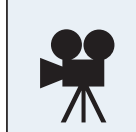

See the following video online:

Physical examination of eyelid ptosis. www.cmaj.ca/lookup/suppl/ doi:10.1503/cmaj.140579/-/DC1 